BULLETIN Bulletin hispanique

HISPANIQUE Université Michel de Montaigne Bordeaux

110-1 | 2008

Varia

\title{
Puntuación (y filiación) del Lazarillo
}

Fidel Sebastián Mediavilla

\section{OpenEdition}

\section{Journals}

Edición electrónica

URL: https://journals.openedition.org/bulletinhispanique/445

DOI: 10.4000/bulletinhispanique.445

ISSN: $1775-3821$

\section{Editor}

Presses universitaires de Bordeaux

\section{Edición impresa}

Fecha de publicación: 1 junio 2008

Paginación: 61-90

ISBN: 978-2-86781-511-9

ISSN: 0007-4640

\section{Referencia electrónica}

Fidel Sebastián Mediavilla, «Puntuación (y filiación) del Lazarillo», Bulletin hispanique [En línea], 110-1 | 2008, Publicado el 19 diciembre 2011, consultado el 18 septiembre 2021. URL: http://

journals.openedition.org/bulletinhispanique/445 ; DOI: https://doi.org/10.4000/bulletinhispanique.445 


\title{
Puntuación (y filiación) del Lazarillo
}

\author{
Fidel Sebastián Mediavilla \\ Universidad Autónoma de Barcelona
}

L'analyse exhaustive de la ponctuation des quatre éditions du Lazarillo de 1554 confirme que celles-ci découlent, en dernière analyse, d'un archétype commun (X), imprimé, qui serait antérieur à cette année; que l'édition de Burgos est la plus proche de X; et celle d'Anvers, la plus éloignée. Il s'ensuit, de plus, que le Lazarillo castigado (1573) a pris pour modèle l'édition d'Anvers, et non un exemplaire antérieur à X: les variantes qu'il présente sont ope ingenii.

El análisis exhaustivo de la puntuación de las cuatro ediciones del Lazarillo de 1554 corrobora que todas ellas proceden en última instancia de un arquetipo común (X), impreso, anterior a ese año; que la de Burgos es la más próxima en la transmisión de $\mathrm{X}$ y la de Amberes la más alejada. Confirma, además, que el Lazarillo castigado (1573) tiene como modelo la de Amberes y no un ejemplar anterior a X: sus variantes son ope ingenii.

The comprehensive analysis of the punctuation in the four 1554 editions of Lazarillo confirms that they all come from the same printed archetype $(X)$, thought to be older, and that the Burgos edition is the closest to $X$, the Antwerp edition being the most divergent. Therefore Lazarillo castigado (1573) followed the Antwerp model and not a copy prior to $X$ : their variants are ope ingenii.

Mots-clés : Ponctuation - Filiation - Lazarillo - Orthographe.

$B H i$, Tome 110, n 1 - juin 2008 - p. 61 à 90. 
$\mathrm{E}$ S DE TODOs sabido que no se conoce la edición princeps del Lazarillo, y que las ediciones más antiguas están fechadas en un mismo año, el de 1554: una en Burgos, en casa de Juan de Junta; otra en Alcalá de Henares, en la imprenta de Salcedo ; una más en Medina del Campo, en el taller de los hermanos Mateo y Francisco del Canto ; y una cuarta en Amberes, en casa de Martín Nucio (en adelante las citaremos por la ciudad en que se estamparon o con las siglas $B$ para referirnos a la de Burgos, $A$ a la de Alcalá, $M$ a la de Medina y $C$ a la de Amberes). Hasta 1992 sólo se conocían tres de ellas $(A, B$ y $C)$.

Cuando todavía no se tenía noticia de la existencia del impreso de Medina del Campo (descubierto por azar ese año, y publicado por primera vez en 1995) ${ }^{1}$, Alberto Blecua, buscando pruebas que aclarasen las relaciones entre las tres ediciones, y las de cada una de ellas con respecto al texto original, abría una vía nueva a la investigación: «la solución (...) existe y es tan elemental, que por esto mismo ha pasado inadvertida, que yo sepa, hasta ahora. La llave que nos abre los secretos de la transmisión textual del Lazarillo no es otra que la puntuación de los tres textos de $1554 »^{2}$. Sin embargo, en aquella ocasión se limitó a un cotejo somero, sin apurar el estudio de las peculiaridades, coincidencias y discrepancias que manifiestan los textos en cuanto a su puntuación.

No consta que nadie lo haya hecho hasta el momento. Confiados, por tanto, en que el terreno que nos proponemos explorar es prometedor, vamos a intentar realizar un estudio sistemático de las cuatro ediciones de 1554 . Para ello, hemos utilizado la nítida edición facsimilar preparada por A. Pérez Gómez $^{3}$, que contiene los textos de Alcalá, Burgos y Amberes; y el facsimil de la edición de Medina del Campo preparado por Cañas Murillo ${ }^{4}$. También hemos podido ver la esmerada reproducción de uno de los ejemplares de la de Amberes que se conserva en la Biblioteca Nacional Española, recientemente publicada junto con un estudio crítico de Bienvenido Morros ${ }^{5}$. Cuando se nos han presentado dudas acerca de la identidad de algún signo, hemos acudido a los originales, o a un microfilm que ofreciera una lectura sin sospecha ${ }^{6}$. Hemos introducido la totalidad del texto en el ordenador, y,

1. Véase el estudio de Jesús Cañas Murillo, "Una edición descubierta de Lazarillo de Tormes: Medina del Campo, 1554», que sirve de presentación a la edición facsimilar (Editora Regional de Extremadura, Mérida, 1996).

2. «Introducción» a su edición del Lazarillo, Castalia, Madrid, 1972, p. 54.

3. Cieza, 1959. Va precedida de un prólogo de E. Moreno Báez.

4. Citado más arriba, en la nota 1.

5. AyN Ediciones, Madrid, 2004.

6. La edición a tres columnas de Ricapito nos ha sido útil para localizar los lugares paralelos, 
con su auxilio, hemos podido realizar, además del recuento de los signos, la colación de coincidencias y variantes, extraer cantidades absolutas y porcentajes. Se trata de ver lo que pueden revelar los grandes números y las diferencias. Consideramos que la coincidencia de dos o más ediciones en un error o desviación de puntuación constituye prueba de que esos textos son descendientes más o menos directos de una misma fuente, de un mismo arquetipo. Por otra parte, si, dentro de un sistema de puntuación muy irregular - por falta de reglas y por una práctica poco responsable-, varias ediciones presentan un porcentaje muy alto de coincidencias, pueden estar mostrando de otro modo, o confirmando, su pertenencia a una misma rama de transmisión textual.

Antes que nada, conviene que hagamos una ligera descripción de los sistemas de puntuación por los que se rigen las ediciones. En las referencias textuales destacaremos en negrita el signo que se desea mostrar, y las dos palabras contiguas -anterior y posterior-al mismo, con el objeto de facilitar su localización.

\section{ENTRE DOS SISTEMAS DE PUNTUACIÓN}

A lo largo de los siglos XVI y XVII la puntuación en los textos impresos muestra una lenta transición desde una puntuación antigua, con la que se intenta imitar -como en los demás aspectos formales- a los códices manuscritos, y una puntuación nueva, por la que apuestan algunos de los más competentes editores -en particular los Manuzio de Venecia-, siguiendo las prácticas recientemente introducidas por los humanistas italianos ${ }^{7}$. El prestigio de estos editores contribuyó en gran medida a la imitación de sus tipos y a tomarlos como modelos en el arte de puntuar ${ }^{8}$.

pero, como cabe esperar de toda copia, contiene no pocas erratas que la incapacitan como referencia. (Nos referimos a A Tri-linear Edition of Lazarillo de Tormes of 1554 Burgos, Alcalá de Henares, Amberes; edited by J.V. Ricapito, Madison (Wis.), Hispanic Seminary of Medieval Studies, 1987).

7. Véase a este respecto Fidel Sebastián, Puntuación, humanismo e imprenta en el Siglo de Oro, Academia del Hispanismo, Vigo, 2007.

8. Entre otros gramáticos, Jiménez Patón, en su Ortographia (1614), los pone de ejemplo: "Véase a Calepino en las más modernas impresiones que advirtiendo en él, se hallará copia de exemplos de nuestra dotrina, y en los libros impresos por el grifo y por plantina [sic], que son las mejores impresiones, y aquellas en que asistieron Aldo o Paulo Manucio, padre e hijo». Bartolomé Jiménez Patón, Epitome de la ortografía latina y castellana. Instituciones de la gramática española, ed. Antonio Quilis y Juan Manuel Rozas. Consejo Superior de Investigaciones Científicas, Madrid, 1965, p. 78. El texto de Jiménez Patón se recoge en Puntuación, humanismo e imprenta en el Siglo de Oro, pp. 50 y 116-117. 
Una puntuación arcaizante suele ir asociada a los tipos góticos (en estos caracteres están impresas las tres ediciones peninsulares del Lazarillo). En este sistema, el único signo que tiene una función insustituible es el punto, para señalar el final de la frase. Toda pausa que se quiera marcar dentro de ella es arbitrariamente señalada por cualquiera de estos tres signos: la barra -o vírgula oblicua- [/], los dos puntos [:] y la moderna coma [,]. Burgos usa de los cuatro, mientras que Alcalá y Medina, sólo tres: además del punto, utilizan la coma y los dos puntos indiferenciadamente, en proporciones distintas, como se verá. Dentro de este sistema de puntuación, la edición que sigue los gustos más arcaizantes es la de Burgos, que, aparte de decantarse decididamente por la vírgula oblicua en una proporción notable sobre el total de signos empleados (34,8\%) -frente a las otras ediciones, que no la usan $^{9}$-, prefiere claramente los dos puntos a la coma, o vírgula curva, a diferencia de la mayor beligerancia que tanto Alcalá como Medina dan a este signo de puntuación emergente. Los paréntesis cumplen la función de acotar un inciso, y son fácilmente sustituibles por la coma. Finalmente, el interrogante se usa con mayor o menor acierto para señalar el fin de una frase con entonación interrogativa, y alguna vez las exclamativas.

La de Amberes es la edición más modernizante, y disidente con respecto a las otras tres: correctora, podríamos decir con propiedad. Escrita en letra redonda, utiliza el sistema de los tres puntos: el punto, los dos puntos y la coma. Aplica, como las otras tres ediciones, el interrogante y el paréntesis. La coma es el signo que utiliza más; supone el 75,19\% sobre el total de sus signos de puntuación: este es un rasgo de modernidad, que anticipa el triunfo progresivo de la coma como el signo más socorrido para escritores y editores de las generaciones siguientes. A los dos puntos se les asignan en Amberes funciones diversas: de una parte sirven para dar entrada a una frase en estilo directo ${ }^{10}$, si bien esta función la comparten con la coma y, sobre todo con el punto y seguido; en otros casos, los dos puntos señalan una pausa de carácter entonativo, el tránsito de la prótasis a la apódosis de la oración, el momento en que la entonación ascendente llega a su cima y comienza el descenso de la voz, independientemente de que la frase sea más o menos larga: a veces prima el propósito de facilitar la respiración; otras, el marcar un silencio expresivo ${ }^{11}$. Y las más de las veces opera como un signo

9. A excepción de una barra oblicua que ostenta inusitadamente en su portada la edición de Alcalá: nota 19. $\left(\mathrm{A} 6^{\mathrm{v}}\right)$.

10. y dixome: Necio aprende que el moço del ciego vn punto ha de saber mas que el diablo,

11. Y a los que no ahondaren tanto: los deleyte, (A2) Esta función de los dos puntos -el colon - la recoge, entre otros, Jiménez Patón en su Ortographia, ed. cit., p. 76: «Miembro 
comodín que lo mismo -o mejor- podría ser sustituido por un punto ${ }^{12} \mathrm{o}$ una coma ${ }^{13}$.

Tanto en la edición facsimilar de Pérez Gómez, como en la transcripción paleográfica de Ricapito ${ }^{14}$, aparecen sendos punto-y-comas en $A^{15}$ y en $C^{16}$, que podrían formar parte de esas apariciones esporádicas del signo en textos anteriores a la difusión del mismo, de los que da cuenta Parkes ${ }^{17}$. Sin embargo, habiendo experimentado ya en otras ocasiones que estas reproducciones aisladas de punto y coma en textos que no lo usan más, suelen provenir de defectos de la copia utilizada ${ }^{18}$, hemos ido a ver los ejemplares de la edición de Amberes que se conservan en la Biblioteca Nacional de Madrid y en el British Museum de Londres, y en ninguno de ellos figura en ese lugar nada más que una coma nitidísima: la apariencia de punto y coma necesariamente se formó en alguna de las fases de reproducción de las copias. En cuanto al único ejemplar conocido de la edición de Alcalá, que se guarda en la biblioteca del museo inglés, sobre la coma, que acaba línea, hay una ligera mácula que ha dado lugar a la apariencia de punto y coma en las copias y ampliaciones. Tras esta minuciosa comprobación, podemos afirmar con toda seguridad que en las ediciones del Lazarillo de 1554 no se usa el punto y coma. En cambio, y de modo excepcional, una barra oblicua, en solitario, destaca justamente en el título de la portada de la edición complutense ${ }^{19}$.

o colon es vn punto sobre otro, de esta manera (:), con el qual se diuiden los principales miembros de la cláusula, quando parece que la oración se a acabado, mas el ánimo del que oye queda suspenso, esperando otra cosa que depende de lo dicho». Véase Puntuación, humanismo e imprenta, p. 69.

12. Yo oro, ni plata no te lo puedo dar, mas auisos para biuir muchos te mostrare: $y$ fue assi que despues de Dios este me dio la vida, y siendo ciego me alumbro y adestro en la carrera de biuir. $\left(\mathrm{A} 6^{v}\right)$.

13. Mas de que vi que con su venida mejorana el comer, fuyle queriendo bien, porque siempre traya pan: pedaços de carne, y en el inuierno leños a que nos calentauamos. (A5).

14. Cfr. nota 6.

15. De que esto me oyeron; van por vn alguazil y vn escriuano, y helos do bueluen luego con ellos, (Eiiv). En este lugar $B$ y $M$ imprimen los usuales dos puntos, mientras $C$ recurre a la moderna coma, como hace en realidad $A$.

16. y venimos a este camino por los mejores lugares; donde hallaua buena acogida y ganancia, deteniamonos, donde no a tercero dia haziamos sant Iuan. (A10v). Se trata de una corrección intencional a la moderna para superar la confusión que en ese pasaje siembran los otros tres por omitir toda puntuación. $C$ lo hace con una coma insuficiente.

17. Cfr. M.B. Parkes, Pause and effect, University of California Press, Berkeley, Los Angeles, 1993, p. 52.

18. Así lo hicimos al estudiar la puntuación de la princeps del Quijote (vid. infra, nota 53), que no usa este tipo en absoluto.

19. La vida de Lazarillo de Tormes / y de sus fortunas: $y$ adversidades. Como se puede 
Veamos en un cuadro esquemático la distribución de los diversos signos de puntuación en los cuatro textos (para el cómputo, no hemos considerado las adiciones que trae Alcalá que, por otra parte, siguen las mismas pautas que el resto de la obra).

Tabla 1: distribución de signos de puntuación, con sus cantidades absolutas

\begin{tabular}{|l|c|c|c|c|}
\hline \multicolumn{1}{|c|}{ SIGNOS } & BURGOS & ALCALÁ & MEDINA & AMBERES \\
\hline / (barra o vírgula oblicua) & 718 & 1 & 0 & 0 \\
\hline : (dos puntos) & 775 & 460 & 788 & 26 \\
\hline . (punto) & 474 & 430 & 434 & 462 \\
\hline , (coma o vírgula curva) & 52 & 1113 & 711 & 1652 \\
\hline ( ) (paréntesis) & 33 & 7 & 28 & 33 \\
\hline ? (interrogante) & 18 & 12 & 17 & 23 \\
\hline total signos & 2070 & 2023 & 1978 & 2196 \\
\hline
\end{tabular}

\section{COINCIDENCIAS EN LAS CUATRO EDICIONES}

En unos sistemas abiertos - poco definidos- de puntuación, como los que siguen los cuatro impresos del Lazarillo, hemos de tener en cuenta que algunos signos son, en principio, equivalentes e intercambiables, como la coma, la barra y los dos puntos; o intercambiables en algunas situaciones, como, por ejemplo, el punto, la coma y los dos puntos para dar entrada a una frase de estilo directo. Por lo tanto, a la hora de buscar las coincidencias -los grandes números- lo que nos interesa es notar si en el mismo lugar los textos señalan pausa o no la señalan, independientemente del signo que empleen. Cuando se trate de las diferencias, en cambio, habremos de atender no sólo a las ausencias frente a presencias de signos de puntuación, sino también a si uno o varios impresos optan -frente a los otros- por un signo cuyo valor es manifiestamente diferente o produce deturpación en el texto.

La coincidencia de lugares en que se marca pausa con uno u otro signo de puntuación en las cuatro ediciones del Lazarillo es considerablemente alta, si se tiene en cuenta, además de la subjetividad del autor, del amanuense y del corrector a la hora de puntuar, la libertad con que aplicaban la ortografía los cajistas de las imprentas. Los cuatro textos coinciden en un 63,66\% de

apreciar, es una variante de los dos puntos que se usan a continuación en el mismo contexto y circunstancia. 
pausas marcadas en los mismos lugares. Este dato habla a favor de su filiación -más o menos próxima- con respecto a un mismo arquetipo impreso. Así lo valora Rico, quien escribía en 1988: "Absolutamente insólito sería que tres amanuenses hubieran respetado con tanto rigor la puntuación de un arquetipo 'de mano'; pero que, además, tres cajistas se hubieran ceñido a esos tres códices con tal fidelidad es por entero inconcebible» ${ }^{20}$. Según este razonamiento, también Medina se sumaría a los descendientes de un mismo impreso anterior, puesto que participa, con los otros tres, de un alto grado de coincidencias de puntuación.

Siendo todos ellos tan concordes en señalar pausa en los mismos lugares -independientemente del acierto o desacierto de esa puntuación, y del tipo de signo elegido-, conviene que notemos las distintas proporciones de coincidencias de unas ediciones con respecto a las demás. Los textos menos coincidentes son Burgos y Amberes, con un 61,4\% de pausas comunes, frente al 77,4\% de coincidencias entre Alcalá y Medina, el 75,72\% de Medina-Amberes, el 73,33 \% de Alcalá-Amberes, el 68 \% de Burgos-Alcalá, y el 67,06 de Burgos-Medina.

Del cotejo realizado, merece la pena destacar la fidelidad común al punto. Por ser signo de final de periodo, por venir resaltado por la mayúscula que le sigue, el punto es el signo mayoritariamente respetado por los cuatro impresos $^{21}$. Los cuatro coinciden en 376 puntos, de un total de $474(B)$, $430(A), 434(M)$ y $462(C)$ : es decir, los cuatro coinciden en el 83,55\% de los puntos, como término medio. El respeto al punto se traslada incluso a lugares en que éste es opcional, como cuando presenta una frase en estilo directo $^{22}$.

20. Francisco Rico, «La princeps del Lazarillo. Título, capitulación y epígrafe de un texto apócrifo", Problemas del "Lazarillo», Cátedra, Madrid, 1988, p. 116.

21. Por ejemplo: pues podria ser que alguno que las lea / halle algo que le agrade. $Y$ a las que no ahondaren tanto los deleyte / $\left(B A^{v}\right)$. En este pasaje, el punto es el único signo que repiten las cuatro ediciones, mientras que en los demás presentan toda suerte de variantes. Así, $A$ imprime: pues podria ser que alguno que las lea, halle algo que le agrade. $Y$ a las que no ahondaren tanto, los deleyte, ; $M$ trae: pues podria ser que alguno que las lea, halle algo que le agrade. $Y$ a las que no ahondaren tanto, los deleyte,; y $C$ : pues podria ser que alguno que las lea, halle algo que le agrade. $Y$ a los que no ahondaren tanto: los deleyte $(C$ corrige las que por los que).

22. Son 32 (un 49,23\%) los casos en que las cuatro ediciones usan unánimemente punto después del verbo 'dezir' para introducir un parlamento en estilo directo. Por ejemplo:

y como me viesse de buen ingenio / holgauase mucho : y dezia. Yo oro ni plata no te lo puedo dar / mas auisos para viuir muchos te mostrare.(B Av).

$\mathrm{Y}$ lugares paralelos. O:

Luego el tornaua a dar bozes diziendo. Mandan rezar tal y tal oracion: como suelen dezir. (B Avii). 
Peculiares son tanto el uso de la barra en $B$ (por ser el único impreso que la emplea), como el cambio casi automático que hace $A$ de los paréntesis de las otras ediciones por dos comas encerrando el mismo pasaje: la edición de Alcalá sólo trae 7 paréntesis, mientras opta por las comas en otras 19 ocasiones en que los demás son unánimes ${ }^{23}$.

\section{VARIANTES DIGNAS DE CONSIDERACIÓN}

Consideramos variantes dignas de mención aquellas que se presentan en dos o más impresos como excepciones a su propio sistema de puntuar: pueden llamarse, por lo tanto, errores de puntuación. Si su existencia no puede ser justificada por error accidental del cajista, delatan que, si el uno no ha copiado al otro, los textos que presentan el mismo error provienen, más o menos directamente, de un mismo arquetipo. Su valor probatorio tiene la misma fuerza que las variantes léxicas, morfológicas o sintácticas compartidas.

\section{A. Errores comunes a las cuatro ediciones.}

Hemos colacionado un mínimo de 12 errores de puntuación compartidos por las cuatro ediciones. Traemos aquí una selección de ellos y, a continuación, indicaremos la localización de los restantes:

1. B Avi Digo verdad si con mi sotileza y buenas mañas no me supiera remediar: muchas vezes me finara de hambre:

Sin puntuación también en $A, M y$ y .

La redacción que encontramos en los cuatro impresos induce a una lectura errada, pues la ausencia de marca después de verdad lleva a interpretar la proposición introducida por si como subordinada del verbo digo, cuando, en

Y los pasajes correspondientes en las otras tres ediciones, que también traen el punto y seguido.

23. Baste un ejemplo para muestra. Mientras $B$ escribe:

$Y$ quando alguno de estos escapaua (Dios me lo perdone) que mil vezes le daua al diablo. (B Bviiv),

y $M$ y $C$ también acotan con paréntesis, $A$ lo hace con comas:

Y quando alguno destos escapaua, Dios me lo perdone, que mil vezes le daua al Diablo, (A Bvii). 
realidad, depende de finara. Construcciones semejantes se resuelven en otros pasajes indicando pausa delante de la conjunción. Por ejemplo:

$Y$ en esto yo siempre le lleuaua por los peores caminos: y adrede por le hazer mal y daño: si auia piedras por ellas : si lodo : por lo mas alto: (B Aviiii ${ }^{\mathrm{v}}$.

Alcalá y Medina, en este lugar, observan los dos puntos también, mientras Amberes opta por la coma, como hace las más de las veces. El texto se ayuda de uno u otro signo de puntuación para aclarar de inmediato que la condicional depende de lo que sigue, y no de lo que antecede. En otro caso, tan sólo Alcalá es sensible a este problema, y distingue la condicional de lo que la antecede con una coma, dando la lectura mejor:

dime prissa, porque le vi en disposicion, si acabaua antes que yo, se comediria a ayudarme a lo que me quedasse: (A Cviii ${ }^{v}$ ).

Todavía otro ejemplo de actuación ante un pasaje que reclama la observancia de pausa para ser entendido. En él, puntúan las cuatro ediciones:

informauase de la sufficiencia dellos: si dezian que entendian / no hablaua palabra en latin por no dar tropeçon / (B Eviii).

Medina emplea en este lugar también los dos puntos, mientras Alcalá y Amberes usan la coma.

El error conjunto de las cuatro copias denuncia que todas proceden de una misma fuente de la que lo heredan.

\section{B Aviii y sonrriendose dezia. Que te parece Lazaro lo que te enfermo te sana I}

Igual en $\mathrm{A}$, en $\mathrm{M}$ y en $\mathrm{C}$. Por más que sea dentro del parlamento de una misma persona, el fin de una entonación interrogativa -o bien exclamativareclama un signo de interrogación, o, cuando menos, algún otro signo que señale suficientemente el tránsito de una oración a la otra. Así lo hacen -aunque de forma diferente- los cuatro en otros lugares. Por ejemplo:

como y olistes la longaniza y no el poste ? Ole / ole : le dixe yo. (B Bv):

Donde Burgos pone interrogante, los demás colocan una coma. O en este otro pasaje: 
Que diremos a esto? Nunca auer sentido ratones en esta casa sino agora: $\left(B \mathrm{Ciii}^{\mathrm{v}}\right)$.

Tan sólo Alcalá omite el interrogante y no lo sustituye por otro signo.

$\mathrm{O}$ en este parlamento, también articulado con varias modalidades oracionales -interrogativa primero, y exclamativa después-:

Esta noche moço no sentiste nada : pues tras la culebra anduue $(B \mathrm{Cv})$.

El talante corrector de Amberes le lleva a poner interrogante en el lugar donde los otros emplean dos puntos.

3. B Biiii como llouia rezio y el triste se mojaua / \& con la priessa que lleuauamos de salir del agua que encima de nos caya. $Y$ lo mas principal (porque Dios le cego aquella hora el entendimiento) fue por darme del vengança. Creyose de mi / y dixo:

Error transmitido a las cuatro ediciones. El punto seguido de mayúscula, y un paréntesis que no tiene justificación alguna, ni lugar comparable en todo el texto -la edición $A$, como hace casi siempre, sustituye el paréntesis por coma-, hacen prácticamente incomprensible el pasaje. Con puntuación a la moderna ${ }^{24}$, el pasaje sería: Como llovia recio y el triste se mojaba, y con la priesa que llevábamos de salir del agua, que encima de nos caí, y, lo mas principal, porque Dios le cegó aquella hora el entendimiento (fue por darme de él venganza), creyóse de mí y dixo ${ }^{25}$.

4. B Eiii $Y$ no es buena maña de saludar vn hombre ha otro / dixe yo.

Dezirle que le mantenga Dios.

Igual en $A, M$ y $C$. Este punto, y mayúscula a continuación, es error notorio en todas y cada una de las cuatro ediciones. No tiene justificación una pausa de esta categoría en un simple inciso que interrumpe momentáneamente al interlocutor que va a continuar hablando. Por otra parte, no se recoge ningún pasaje semejante tratado de este modo en ninguna de las ediciones de 1554. El comportamiento usual en situaciones semejantes consiste en marcar pausa con un signo de menor entidad. Por ejemplo, el paréntesis:

24. Entre las ediciones modernas, véanse la de José Caso González, Anejos del Boletín de la Real Academia Española, anejo xvii, Madrid, 1967; la de Alberto Blecua, Castalia, Madrid, 1972 y la de Francisco Rico, Cátedra, Madrid, 1988 (citaré por la 13ª, 1998).

25. Ed. de Francisco Rico, p. 45. 
$O$ señor mio (dixe yo entonces) a quanta miseria y fortuna y desastres estamos puestos los nascidos / ( $B$ Cii ${ }^{2}$ ):

( $A$, como casi siempre, sustituye en este pasaje los paréntesis por sendas comas); o los dos puntos, o coma:

No señor / dixe yo : que aunque [sic] no eran dadas las ocho / quando con vuestra merced encontre. (B D)

Mientras Alcalá y Medina utilizan la misma puntuación que Burgos para cerrar el inciso, Amberes opta por la coma en este caso. Por delante, Burgos usa una barra en esta ocasión, mientras que Medina y Amberes acuden a la coma, y Alcalá omite puntuación. En otros casos, Burgos echa mano de la barra también para cerrar el inciso que interrumpe la peroración:

Bien te he entendido dixe yo entre mi / maldita tanta medicina y bondad como aquestos mi [sic] amos que yo hallo, hallan en la hambre: $\left(B \mathrm{D}^{\mathrm{v}}\right)$ :

Los otros tres puntúan el pasaje con coma, tomando todos ellos en consideración tan sólo el final del inciso, y no el principio, que dejan sin puntuar.

Otros errores comunes se pueden ver en $B A v^{v}$ (effectos para); Aviv (desdicha: tambien); Biiv (vino alguno); Biiv (podenco por... lleuaua asiendome); Cviv (dixe que); Eiiv (señor le dixe yo que); Eiiii (contentar a estos [?]); $\mathrm{Ev}^{v}$ (duda dizen ellos esta), y lugares paralelos de las otras ediciones.

\section{B. Errores de puntuación compartidos por $B, A$ y $M$}

Son sin duda los más cuantiosos. Hemos recogido 28 , de los cuales transcribimos una pequeña selección, acompañada de los comentarios más indispensables.

1. B Avi Despues que cerraua el candado y se descuydaua pensando que yo estaua entendiendo en otras cosas. Por vn poco de costura que muchas vezes del vn lado del fardel descosia y tornaua a coser: sangrana el auariento fardel socando [sic] / no por tassa pan: mas buenos pedaços: torreznos y longaniza:

Tanto $A$ como $M$ reproducen el punto. El verbo principal es sangraud. La lectura de todo lo que antecede está pendiente de encontrar el verbo, que 
tarda en desvelarse. El punto rompe absolutamente el ritmo, el sentido y la lógica de la frase. Es un error sin justificación: que incurran en él los tres textos sólo puede tener explicación en que siguen acríticamente una misma tradición, provienen más o menos próximamente de un arquetipo o subarquetipo que lo contiene. Amberes lee adecuadamente, mediante una coma:

C A8 despues que cerraua el candado y se descuydaua pensando que yo estaua entendiendo en otras cosas, por vn poco de costura que muchas vezes del vn lado del fardel descosia y tornaua a coser, sangraua el auariento fardel sacando no por tassa pan, mas buenos pedaços, torresnos y longaniza:

2. $B \mathrm{~B}$ \& venimos a este camino por los mejores lugares donde hallaua buena acogida \& ganancia deteniamonos donde no a tercero dia haziamos sant Juan.

Igual en $A$ y en $M$. El error en Burgos, Alcalá y Medina entorpece mucho la lectura y ofrece dudas al lector. Una frase termina en lugares y otra empieza a continuación. La complejidad de las subordinadas de esta larga frase pudo llevar a los correctores de las tres imprentas a no reparar en la necesidad de una pausa indispensable para la interpretación del pasaje. La explicación ha de estar en la herencia de un error contenido en un texto anterior a ellos. Es correcta la lectura que Amberes hace del mismo pasaje, colocando acertadamente la puntuación:

$C \mathrm{~A} 10^{\mathrm{v}}$ y venimos a este camino por los mejores lugares: donde hallaua buena acogida y ganancia, deteniamonos, donde no a tercero dia haziamos sant Iuan.

3. B Biiiv lauaronme la cara y la garganta: sobre lo qual discantaua el mal ciego: donayres diziendo: por verdad mas vino me gasta este moço en lauatorios al cabo del año que yo beuo en dos.

$A$ y $M$ traen también pausa ( $A$ una coma en lugar de dos puntos). En la frase, donayres es el complemento directo del verbo discantar ('cantar' según el Diccionario de Autoridades ${ }^{26}$ ). La pausa interpuesta entre ciego y donayres deja el texto sin sentido. El error puede venir por la atracción del verbo dezir, que invita al componedor a quedarse con el esquema «donayres diziendo:».

26. Y añade Autoridades: «Usase freqüentemente por componer, hacer ù dezir versos». En otras de sus acepciones: «Vale tambien glossar ó añadir alguna cosa à otra, ò hablar mucho sobre alguna materia.» 
En cualquier caso, esta sería la causa que llevó al error a un editor anterior, pues la incursión de los tres en el error no tiene más explicación plausible que la vinculación, a través de unos u otros caminos, de un modelo último común, que lo contenía (salvo -y no es el caso- que se hubieran copiado entre sí). $C$, una vez más, corrige:

$C \mathrm{~B}^{\mathrm{v}}$ lauaronme la cara y la garganta, sobre lo qual discantaua el mal ciego donayres diziendo, por verdad mas vino me gasta este moço en lauatorios al cabo del año que yo beuo en dos.

4. B Bviii pues estando en tal aflicion / qual plega al señor librar della a todo fiel christiano y sin saber darme consejo / viendome yr de mal en peor. Un dia quel cuytado / ruyn y lazerado de mi amo auia ydo fuera del lugar llegose acaso a mi puerta vn calderero:

Igual en $A$ y $M$. Burgos, Alcalá y Medina insertan un punto que interrumpe no sólo la entonación, sino el sentido de la frase. Es tan inexplicable sintácticamente, que su aparición en las tres ediciones requiere acudir a la explicación del error común. $C$, en lugar del punto, trae una coma.

5. B Ciiii De que vio no le aprouechar nada su remedio (dixo) este arcaz esta tan maltratado y es de madera tan vieja y flaca que no aura raton a quien se defienda I

$B$ y $M$ cometen la misma falta: tratar dixo como un inciso en medio de parlamento, cuando, por el contrario, da entrada a una intervención. $A$ sigue la misma lectura, a su manera, que es poner coma donde las otras ediciones ponen paréntesis. El inciso inoportuno, y el paréntesis, que únicamente aparece una vez para marcar-cuando lo es-el inciso dixo ${ }^{27}$, sólo se entienden como error común: los tres han copiado acríticamente de textos que a su vez

27. El único pasaje en que aparece la palabra dixo entre paréntesis en función de inciso es el que sigue: Yo te digo (dixo [)]que si un hombre en el mundo ha de ser bienauenturado con vino que seras tu. (B Biiii): Burgos omite por error el paréntesis de cierre, que sí imprimen Medina y Amberes. Alcalá usa sus habituales comas precedente y subsiguiente. En otros lugares, frecuentes, el inciso o no se puntúa, o se hace con otro tipo de signos: Yo hizeme muy marauillado preguntandole que seria / que ha de ser dixo el : ratones que no dexan cosa a vida: ( $B$ Cii): los dos puntos de Burgos son coma en las otras ediciones. O este otro: Uirtud es essa dixo el / y por esso te querre yo mas: $(B \mathrm{D})$ : Burgos coloca vírgula, Amberes coma, y Alcalá y Medina omiten puntuación. (La construcción dixe yo haciendo inciso a un parlamento en primera persona aparece regularmente acotada con paréntesis -Alcalá con comas- en cuatro ocasiones: $B$ C, $\mathrm{Cii}^{\mathrm{v}}$, $\mathrm{D}^{\mathrm{v}}$, Dvivi , y paralelos). 
han copiado este error de otros, hasta llegar a uno primero del que todos ellos descienden con parentesco de mayor o menor grado. La lectura que da $C$ es correcta:

$C$ B9v De que vio no le aprouechar nada su remedio, dixo: Este arcaz esta tan maltratado y es de madera tan vieja y flaca que no aura raton a quien se defienda,

6. B Dvi Agora pues como [sic] peccador (que si a Dios plaze) presto nos veremos sin necessidad.

A Diiii agora pues come pecador, que si a dios plaze, presto nos veremos sin necessidad,

$M$ Eviii agora pues come peccador (que si a Dios plaze) presto nos veremos sin necessidad:

$C \mathrm{C}^{\mathrm{v}}$ agora pues come pecador que (si a Dios plaze) presto nos veremos sin necessidad,

El paréntesis de apertura está colocado en un lugar erróneo, tanto en $B$, como en $A$ y $M$. Sólo $C$ proporciona con su puntuación una lectura correcta: acota entre paréntesis un inciso que, si desapareciera, no impediría la inteligencia del mensaje -esa es propiamente la misión del paréntesis. El signo primero está torpemente anticipado en las otras tres ediciones, que incurren, sin duda, en el mismo error (recordemos que las dos comas de Alcalá corresponden a su modo habitual de acotar los paréntesis).

Otros errores comunes a estas tres ediciones se pueden localizar en $B$ Aii (viuir / no); B (lugares donde); B (mano para); Biiii (voluntad. Con); Bvi ${ }^{\mathrm{v}}$ (remediaran para); Ciii (arcaz. Senti); Cv (nada: pues); Cviii (yglesia a); D (Pues aunque de mañana yo); Dv (huuiste / si); Diiii (almorzado.); Dvii (el peccado[r]. En); Dvii (camisa. Subio); Ev (trayan arrimeme); $\mathrm{Ev}^{\mathrm{v}}$ (preguntauan / bien); Evi (preguntaron: en); Evii ${ }^{v}$ (bulla. Primero); Eviii (se / acordo); Fiii ${ }^{v}$ (cantado. El); Fiiii (negocio. Conosci); Fiiiiv (medida daua); Fviv (trigo por) y paralelos de $A$ y $M$.

El carácter corrector que tiene el texto de Amberes lo hace merecedor de imitación. De tal manera que las ediciones posteriores a 1554 se harán a partir de ésta ${ }^{28}$. Si la edición que merece el aplauso de sus contemporáneos lee de manera diferente en estos pasajes, es porque los considera error.

28. Cfr. la «Introducción» a la edición del Lazarillo de Alberto Blecua, 1972, pp. 59 y ss. 


\section{Errores compartidos por $B$ y $M$}

La edición de Medina del Campo presenta variantes de puntuación compartidas con la de Burgos, que denotan entre ellas un parentesco particular, dentro de la general dependencia que los cuatro escritos parecen tener con respecto a un mismo arquetipo.

Veamos algunas de estas variantes, en particular:

1. $B \mathrm{~B}$ \& venimos a este camino por los mejores lugares donde hallaua buena acogida \& ganancia deteniamonos donde no a tercero dia haziamos sant Juan.

$B$ y $M$ omiten la coma que $A$ y $C$ insertan después de deteniamonos. Ya nos hemos ocupado de este pasaje más arriba, para tratar de un error común a las ediciones de Burgos, Alcalá y Medina. Aquí observamos un error compartido tan sólo por Burgos y Medina, que omiten una coma necesaria para comprender dónde acaba una oración y dónde comienza la siguiente. Amberes mejora la lectura completando la puntuación. Puntuado a la moderna, queda así: $Y$ venimos a este camino por los mejores lugares. Donde hallaba buena acogida y ganancia, deteníamonos; donde no, a tercero dia haciamos Sant Juan. ${ }^{29}$

\section{2. $B \mathrm{Cv}^{v}$ Quisieron mis hados (o por mejor dezir) mis peccados} que vna noche que estana durmiendo:

También $M$ inserta en lugar indebido el primer paréntesis, que $A$ y $C$ colocan adecuadamente después de la conjunción $o$ : (por mejor dezir). No es concebible la colocación del inicio del paréntesis fuera de su lugar si no es por imitación de un mismo modelo que presenta la misma desviación que los emparenta.

\section{B Cvii Lazaro de oy mas eres tuyo / y no mio busca amo y vete con dios}

No era necesaria la coma -que trae $M$ - ni la barra de $B$ delante de la $y$. En cambio, se echa en falta, lo mismo en $B$ que en $M$, la necesaria pausa en el cambio de oración, después de mio. Además, se siente una necesidad especial de pausa -coma usan $A$ y $C$ - en este tipo de frases que pasan de un tono de

29. Ed. de Francisco Rico, p. 35. 
lenguaje a otro: aquí se pasa de la enunciación a la imperación, o al menos al ruego. Por eso, la ausencia de puntuación es significativa, inusual, un error común, heredado. En un pasaje muy parecido, tan sólo Burgos omite puntuación: tu vellaco y gallofero eres busca busca vn amo a quien siruas. ( $B$ Cvii ${ }^{v}$ ): Alcalá estampa dos puntos, y, tanto Medina como Amberes, coma. La ausencia en Burgos puede venir justificada por la sencilla razón de que van en final de línea: presumiblemente, ante la falta de espacio, el cajista opta por la omisión con tal de no tener que volver a componer lo ya compuesto, sin reparar en que esa puntuación no es excusable en esta frase concreta.

4. B Diiv Señor de mi dixe yo / ninguna pena tenga vuestra merced que se passar [sic] vna noche / y aun mas si es menester. Sin comer viuiras mas y mas sano me respondio I

El párrafo se hace ininteligible en $\mathrm{B}$ y $\mathrm{M}$, que escribe igual, por una misma puntuación deficiente: en concreto, por colocar un punto fuera de lugar. Alcalá no es claro en su solución:

\section{$A \mathrm{D}^{\mathrm{v}}$ Señor de mi dixe yo, ninguna pena tenga. U.M. que bien se passar vna noche, y auu [sic] mas si es menester. sin comer. Biuiras mas y mas sano me respondio}

Tan sólo Amberes proporciona una puntuación acorde con el sentido y la entonación de la frase:

C C4 Señor de mi (dixe yo) ninguna pena tenga. V.M. que bien se passar vna noche, y aun mas si es menester sin comer. Biuiras mas sano me respondio,

Quizás $A$ y $C$ corrigen cada uno a su modo.

Otros errores comunes de puntuación diferencian a $B$ y $M$ con respecto a las otras dos ediciones: $B$ Biiiv (bien lleuame); $\mathrm{Cvi}^{\mathrm{v}}$ (sacerdote a); Cviiv (dezian tu) y $\mathrm{D}^{\mathrm{v}}$ (dixome por) y paralelos.

\section{Errores compartidos por $A$ y $M$}

También se alinea la edición de Medina con la de Alcalá en una relación más estrecha que la común descendencia de los cuatro, si nos atenemos a las siguientes variantes: 
1. A $C^{v}$ Lazaro mira, mira que persecucion ha venido aquesta noche por nuestro pan yo hizeme muy marauillado preguntandole que seria,

Alcalá y Medina coinciden en la omisión de un punto absolutamente necesario. Burgos y Amberes lo traen. La explicación más plausible de semejante ausencia sólo puede residir en el descuido que suele producirse en el copista, que se fía del modelo -sobre todo, del modelo impreso-; en este caso, sendos modelos descenderían de un mismo arquetipo o subarquetipo que introdujo por primera vez el error.

2. A Eiiiiv Una lechuga murciana si era por el tiempo vn par de limas, o naranjas, vn melocoton, vn par de duraznos, cada sendas peras verdiñales.

Sin puntuar también en $M . B$ trae barra y $C$ la moderna coma. Ya se ha observado que son repetidas las omisiones de signo de puntuación en el paso de una oración a otra, sobre todo en las ediciones de Burgos, Alcalá y Medina. Sin embargo, esta omisión es especialmente torpe, confunde al lector; se trata de un error tan patente que no puede considerarse casual en dos editores diferentes: la causa se ha de buscar en una fuente común.

\section{A Ev El alguazil puso mano a su espada que en la cinta tenia al ruydo y bozes que todos dimos: acuden los huespedes y vezinos,}

A este caso, que puntúa igual $M$, podemos aplicar la misma valoración que al anterior. Quizás es aquí más necesaria todavía la puntuación, y, por tanto, más llamativa su ausencia ( $B$ inserta barra, y $C$ coma).

Otros errores comunes a las dos ediciones se encuentran en $A \mathrm{D}$ (dixome moço); Diiii (dixo pues) y Evii (otros algunos) y paralelos de $M$.

\section{E. Un error coincidente en $A$ y $C$}

Tan sólo hemos detectado, tras examinar atentamente los cuatro textos, un único error de puntuación de la edición de Amberes, precisamente compartido con la de Alcalá. El error es el siguiente:

A Dvii \& en esta desastrada no hemos de estar mas de en cumpliendo el mes maldita sea ella, 
C C10v y en esta desastrada no hemos de estar mas de en cumpliendo el mes maldita sea ella,

Quizás se podría pasar por alto esta variante, si no fuera por el hecho de que las otras dos ediciones sí han reparado en la necesidad de marcar de alguna manera -con dos puntos- el cambio de entonación que acompaña al cambio de oración. El contexto en que se inscribe este fragmento es, con puntuación de Rico: $Y$ más te hago saber, porque te huelgues: que he alquilado otra casa y en esta desastrada no hemos de estar más de en cumpliendo el mes. ;Maldita sea ella y el que en ella puso la primera teja, que con mal en ella entré! (p. 95). El error compartido no ofrece base suficiente para suponer que los dos impresos derivan de un mismo subarquetipo -porque todos los errores son sanables, y podría ser que unos miembros de la familia hubieran corregido y otros no-, pero justifica al menos la sospecha de un arquetipo intermedio en el que se habría producido ese error, y del que las dos ediciones lo heredarían. Es decir, el error observado no prueba la existencia del subarquetipo, pero la hace plausible.

\section{F. Ediciones que no presentan errores comunes}

Tras un rastreo meticuloso, no hemos localizado ningún error de puntuación compartido por Burgos y Alcalá, ni por Burgos y Amberes, lo cual tiene suma importancia, a la hora de sacar conclusiones.

Los errores de puntuación comunes a varias ediciones que hemos localizado y estudiado se distribuyen, pues, de la siguiente manera:

Tabla 2: número de errores comunes hallados y estudiados

\begin{tabular}{|c|c|c|c|c|c|c|c|}
\hline$B-A-M-C$ & $B-A-M$ & $B-M$ & $A-M$ & $A-C$ & $B-A$ & $B-C$ & $M-C$ \\
\hline 12 & 28 & 8 & 6 & 1 & 0 & 0 & 0 \\
\hline
\end{tabular}

\section{EN LA TRANSMISIÓN TEXTUAL, LA PUNTUACIÓN DEL LAZARILLO CASTIGADO DE VELASCO}

Después de la proliferación de ediciones impresas en el mismo año de 1554 que acabamos de contemplar, vino un tiempo de silencio para el Lazarillo, impuesto por la censura desde ese mismo año según Rico, aunque 
sería en 1559 cuando aparecería incluido en el Catálogo de libros prohibidos, impreso por mandato del inquisidor Fernando de Valdés ${ }^{30}$. Esta prohibición -que incluía la emisión de nuevas copias y la conservación de los ejemplares impresos con anterioridad- es, sin duda, la causa de que tan sólo nos haya llegado un ejemplar de cada una de las ediciones peninsulares, mientras se conservan seis de la antuerpiense ${ }^{31}$.

La confección de un Índice expurgatorio que se publicó en Amberes en 1571 bajo el amparo de Arias Montano abría el camino a la reedición de algunas obras prohibidas, después de someterse a la eliminación de los pasajes censurables $^{32}$. Así, el Lazarillo vio nuevamente la luz, una vez expurgado, en Madrid en 1573. La edición fue encargada a un Juan López de Velasco, que la dio a la imprenta con el título de Lazarillo de Tormes castigado. Impresso con licencia del Consejo de la santa Inquisicion, y con preuilegio de su Magestad, para los reynos de Castilla y Aragon ${ }^{33}$.

En las últimas décadas del siglo pasado, la crítica había compartido unánimemente la aseveración de Alberto Blecua acerca de que «las ediciones posteriores a 1554 descienden de la edición de Amberes y no de textos perdidos» ${ }^{34}$. Esta unanimidad, sin embargo, ha venido después derivando en disensión de algunos estudiosos cuyas apreciaciones han sido recapituladas y defendidas a partir de los noventa por Aldo Ruffinatto ${ }^{35}$.

Ruffinatto plantea que la principal incógnita «de todo este discurso ecdótico (hasta ahora estrechamente vinculado con los principios del método lachmanniano) queda representada por la edición de Velasco, o, mejor dicho, por sus variantes que, en un primer momento, yo tenía pensado que fueran emendationes ope ingenii de aquel "hombre avispado» (en palabras de Caso)

30. Cathalogus librorum qui prohibentur, Valladolid, en la imprenta de Sebastián Martínez. Para la censura y los índices de libros prohibidos en el siglo XVI, cfr. J. M. de Bujanda, directeur, Index des livres interdits, V. Index de l'inquisition espagnole 1551, 1554, 1559, Centre d'Études de la Renaissance, Éditions de l'Université de Sherbrooke, Librairie Droz, Genève, 1984.

31. Cfr. Agustín Redondo, «Censura, literatura y transgresión en época de Felipe II: el Lazarillo castigado de 1573", Edad de Oro, XVIII (1999), pp. 135-149.

32. Nos referimos al Index expurgatorius librorum... iuxta sacri Concilij Tridentini decretum, Philippi II... iussu \& auctoritate, atque Albani Ducis consilio ac ministerio in Belgia concinnatus, Anno M.D.LXXI / (Benedicti Ariae Montani... in correctorium indicem... praefatio). Antuerpiae: ex officina, Christophori Plantini, 1571.

33. Se publicó en un mismo volumen con la Propalladia de Torres Naharro, a continuación de ésta. Abarca los folios 373 a $417^{v}$ (signaturas aa-ggv). Impreso en Madrid, en el taller de Pierres Cosin, 1573. Citamos por el ejemplar de la Bilbioteca Nacional de Madrid R/4610.

34. Cfr. «Introducción» a su edición del Lazarillo, Castalia, Madrid, 1972, p. 59.

35. Por ejemplo en «A propósito de El Lazarillo de Tormes: Medina y las nuevas fronteras textuales del Lazarillo», Voz y letra, IX, n. 2, 1998, pp. 87-121. 
que, en la segunda mitad del XVI, desempeñaba el oficio de Secretario del Consejo de las Indias y que respondía al nombre de Velasco» ${ }^{36}$.

$\mathrm{Y}$, entre otras variantes, invoca las de puntuación, para sacar sus conclusiones. A este respecto hace suya la que había formulado Alfredo Rodríguez López-Vázquez, «quien, tras haber considerado la diferente puntuación de Velasco con respecto a Nucio (=Am) y a Salcedo $(=\mathbf{A l})$, afirma que esto goza de una sola explicación: "Velasco está editando a partir de un texto anterior a Nucio y a Salcedo" ${ }^{37}$.

El problema es que ni Rodríguez conocía la existencia de una Orthographia escrita por el propio Velasco, con su apartado acerca de la puntuación, ni Ruffinatto, que manifiesta más tarde haber tenido noticia de ella ${ }^{38}$, le ha prestado la merecida atención.

Ruffinatto aporta, por otra parte, su propio estudio de variantes del texto "(que parecen auténticas o que, de cualquier modo, no pueden tildarse de errores)» para concluir que " un análisis exhaustivo de la varia lectio de $\mathbf{V e}$, en especial la que confluye en el último de los tres niveles que hemos establecido ${ }^{39}$, nos lleva incuestionablemente hacia un ejemplar no simplemente distinto con respecto al arquetipo $\mathbf{X}^{40}$, sino incluso de más alta calidad; como se vislumbra en las numerosas lecturas auténticas certificadas por Ve frente a errores comunes propios de $\mathbf{A m ~} \mathbf{A l} \mathbf{M e}(=\mathbf{X})$ ». Y acaba diseñando un stemma según el cual Velasco derivaría directamente del «arquetipo de los arquetipos $(\boldsymbol{\Omega})$, es decir, un texto que, si no se identifica precisamente con el original, por lo menos se le acerca mucho» ${ }^{41}$ :

36. Ibid., pp. 110-111.

37. Ibid., p. 112. La cita pertenece al artículo de Rodríguez López-Vázquez «Una hipótesis alternativa al stemma del Lazarillo", en Castilla. Estudios de literatura (Valladolid), 1989, pp. 111-128 [125].

38. La Vida de Lazarillo de Tormes, Clásicos Castalia, 2001, p. 23, nota 36.

39. Este tercer nivel establecido por Ruffinatto «comprende las variantes cuyo caudal cualitativo y el consiguiente grado de autenticidad resulta tan alto que se hace cuando menos improbable la hipótesis de una intervención enmendadora externa (ope ingenii), aunque debida a un "hombre avispado» (en palabras de Caso), como Velasco». Op. cit., pp. $115-116$.

40. $X$ designa al arquetipo de que derivarían más o menos mediatamente las cuatro ediciones conocidas de 1554 .

41. Ibid., p. 121. 


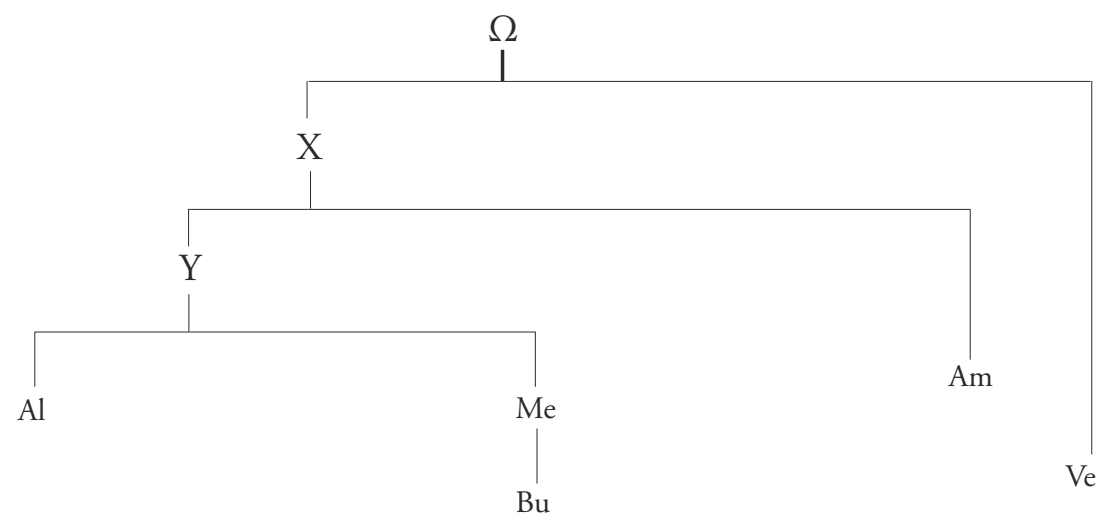

Pero Velasco no sólo era un «hombre avispado», sino un humanista completo, gramático con ideas propias, las cuales no duda en aplicar sistemáticamente a lo largo de todo el texto al que tiene encomendado castigar. Juan López de Velasco era -como gramático y ortógrafo de un siglo en que la ortografía era anárquica-, pedagogo, y, por tanto, corrector. Sus criterios ortográficos -también de puntuación-, después de haberlos puesto en práctica en el Lazarillo de 1573, los puso por escrito, y los publicó en Burgos en 1582, bajo el título Orthographia y pronunciacion castellana ${ }^{42}$. En ella da cuenta de los principios y propuestas -algunas muy personales y exclusivas- que sostiene, y que no son otros que los que él mismo aplica cuando escribe y cuando corrige, con total libertad de espíritu. Por nuestra parte, hemos podido leer y estudiar el ejemplar que se conserva en el Palacio Real de Madrid, y pensamos que, tras su estudio y el cotejo de las variantes de las cinco ediciones, estamos en condición de aportar luz nueva sobre un problema viejo.

Parece ser que el personaje nació hacia 1530 en Vinuesa, al norte de Soria y permaneció en Castilla la Vieja hasta 1565; que después pasó a Madrid, donde vivió hasta su muerte acaecida en 1598. Debió de tener cierta influencia entre los humanistas de la Corte de Felipe II, de cuya Secretaría formó parte. Fue cronista y geógrafo: en los «privilegios» otorgados para imprimir y vender su Orthographia, el Rey le apellida «nuestro Chronista mayor de Indias». Como buen humanista, fue filólogo, amante de la lengua; más,

42. No existe edición moderna: citamos por el ejemplar III/998 de la Biblioteca del Palacio Real de Madrid. En Puntuación, humanismo e imprenta en el Siglo de Oro se transcriben los pasajes relativos a puntuación y acentuación (pp. 38-40 y 103-108). 
escribió, como tantos otros en el Siglo de Oro, una ortografía. Lo hizo, según él mismo declara en la dedicatoria ${ }^{43}$, a instancias del Cardenal Arzobispo de Toledo, don Gaspar de Quiroga, con el intento de poner orden en la pujante lengua vulgar ${ }^{44}$; un tratado que influiría en sus contemporáneos ${ }^{45}$, y poderosamente años después en la doctrina de la Real Academia ${ }^{46}$.

A este Juan López de Velasco se encomendó la expurgación del Lazarillo y su posterior edición. Para esta labor venía provisto no sólo de unas directrices censorias sino también de una conciencia filológica apta para enmendar errores, como lo avala, además de su muy fundamentada Orthographia, el Vocabulario etimológico de la lengua castellana (manuscrito inacabado) y otros textos que igualmente manifiestan verdadera preocupación didáctica ${ }^{47}$.

A la luz de esta vertiente filológica y pedagógica del personaje, toma más cuerpo la verosimilitud de que el origen de las variantes que se observarán en su edición del Lazarillo se deben a la voluntad del editor, y no necesariamente a un modelo diferente de los que conocemos: son variantes ope ingenii.

Pero pasemos a los hechos. Su intervención es audaz y desprovista de complejos: aplica, por ejemplo, a lo largo de todo su Lazarillo un sistema de acentuación absolutamente personal que, como tantos otros intentos reformadores de humanistas del Siglo de Oro, no vería aplicación más allá

43. «A la Magestad del Rey don Philippe II. nuestro señor [sic]». Orthographia, p. 8.

44. "Con desseo que la lengua Castellana, platicada en la mayor parte del mundo (en que vuestra Magestad bien auenturadamente reyna) se escriua bien, como lo merece, para que assi se mejore y ennoblezca: y las gentes estrangeras, que por gusto, o necessidad dessean saberla, la puedan aprender sin el embaraço que hallan en su escriptura incierta y variable: y porque no sea tan justa la culpa, que las otras naciones ponen a la Castellana, en que siendo la lengua tal, ande (como anda) mal escripta:» (Ibid.).

45. Apela a su autoridad como gramático el insigne impresor Guillermo Foquel, editor, en Salamanca, de la obra de Santa Teresa. Autor también él de una Suma de la orthographia castellana (Madrid, 1593), concluye esta obra remitiéndose a la autoridad lingüística del responsable de la edición del Lazarillo castigado: «Todo lo qual podra saberse mas de proposito por el libro de la orthographia Castellana que hizo Iuan Lopez de Velasco. Lavs Deo». También el jesuita P. Francisco Pérez de Náxera reconoce haber tomado como modelo la Ortografía de Velasco (de hecho copia literalmente párrafos enteros y los ejemplos que aduce) para la confección de una cartilla elemental de Orthographia castellana [...] a modo de Dialogo entre dos niños de la escuela, Valladolid, 1604. Años después, en Amsterdam, c. 1663, Abraham de Fonseca publica una réplica de la obra de Náxera justificándola en el título con añadir nueuamente correcta y añadida de algunos avisos y advertencias comvenientes a la buena orthographia escriptura y leyenda (cfr. Puntuación, humanismo e imprenta, pp. 43-48, 108-113 y 131-135).

46. Véase, a este respecto, la monografía de José María Pozuelo Yvancos, López de Velasco en la teoria gramatical del siglo XVI, Universidad de Murcia, 1981: especialmente, pp. 113-121.

47. Hemos complementado el perfil biográfico y la obra de Velasco con el artículo de Agustín Redondo citado más arriba. Redondo sí da cuenta de la Orthographia. 
del propio autor - pensamos, por ejemplo, en las ortografías de Mateo Alemán y de Gonzalo Correas ${ }^{48}$. Cabe preguntarse qué podía detener a un editor capaz de adaptar un texto prácticamente contemporáneo a una ortografía de cuño personal, a la hora de introducir cualquier variante morfológica, sintáctica o léxica cuando lo creyere oportuno para sanar un error o mejorar una lectura.

Ciertamente, lo primero que llama la atención al tomar en las manos la edición de Velasco es la aplicación de acentos a un texto cuyo modelo, el que sea, carecía absolutamente de ellos: no lleva ningún acento ninguna de las ediciones de 1554 -ni las de tipografía gótica $(B, A, M)$, ni la de letrería redonda, $C-$-, y menos los podría llevar una edición anterior. Velasco pone en práctica en su Lazarillo una doctrina original que consiste en puntuar sólo y todas las palabras en las que, si el acento pasara de una sílaba a otra, cambiaría su sentido: aplica una prueba de conmutación avant la lettre: «serâ la regla, para el que quisiere vsar desta curiosidad, y entender quales tienen necessidad desto, trocarles el accento en las sylabas: y quando puesto en las otras donde no le tienen sinificaren algo, señalarsele en la que huuiere menester» (f. 299). Las palabras llanas y esdrújulas que, según este criterio deban ser acentuadas, llevarán acento agudo, y las agudas esdrújulo (ff. 294295). Así, por ejemplo, leemos en el Lazarillo castigado: «Por lo qual fue preso y confessô, y no nego, y padecio persecucion por justicia. Espéro en Dios, que estâ en la gloria pues el euangelio los lláma bienauenturados» (f. $376^{v}$ ).

Donde no había ni un solo acento, Velasco tilda -por decisión propia, elaborada y dada a la publicidad-, el 3,1 \% de las palabras del Lazarillo.

También salta a la vista enseguida otra innovación: el Lazarillo castigado trae de vez en cuando el apóstrofo, que no usan en absoluto las ediciones de 1554. Así por ejemplo: "Mi biuda madre como sin marido, y sin abrigo se viesse, determinô arrimarse a los buenos por ser vno d'ellos» (ibid.). (No obstante, más tarde, al tiempo de redactar la Orthographia, y después de describir la forma y uso del apóstrofo -que dice ser tomado del griego y el italiano-, renunciará a su empleo por considerar que, a fin de cuentas, no es necesario usarlo en castellano, pues tampoco vemos usarlo en latín) ${ }^{49}$.

48. Véase Puntuación, humanismo e imprenta, pp. 115 y 124.

49. «En la escriptura Griega e Italiana, ay otro punto, o señal, que llaman apostropho, y es como el medio punto, o coma, puesto por la parte alta del renglon, donde por auerse juntado dos vocales, vna del fin de vna diccion, y otra del principio de otra se pierde la vna della, como D'amor, por de amor, mill'anni, por mille anni, que aunque en la pronunciacion y lengua Castellana, y en el Latin, se pierde muchas vezes la dicha vocal, en la escriptura, no se quíta, ni ay para que introduzirla, pues tampoco lo vemos vsado en el Latin» (f. 292). 
El talante corrector de López de Velasco se demuestra con toda evidencia en la «Tabla, o indice alphabetico de las palabras Castellanas de dudosa Orthographia» que se extiende a lo largo de 71 planas a dos columnas al final de la Orthographia (ff. V4-Aa7): consiste en un amplio vocabulario en que las palabras que lo han menester se presentan con la grafía que Velasco considera correcta, con remisión a la página o las páginas anteriores donde expone la doctrina que justifica la propuesta.

Ahí se encuentra, por ejemplo, la contestación a la infundada suposición de Rodríguez acerca de la variante nadie te vê hazer (Ve ee6) de la que concluía: "parece claro que el circunflejo está reproduciendo un circunflejo del original» ${ }^{50}$. Como se trata de una palabra que ha menester distinguir el verdadero sentido, viene recogida en la tabla de Velasco: ve, y vê (Orthographia, $\mathrm{Aa} 4^{\mathrm{v}}$ ), con remisión al lugar en que se considera explícitamente el caso en cuestión: "Pero adonde muy claramente se conoce el circunflexo, y es menester, es en la palabra, vê, de ver, que algunos escriben con dos, ee. y no es menester mas de vna, con la nota del circunflexo, a diferencia de, vé, acuto, de yr» (298.b).

Entre esos que escriben ve con dos ee se cuenta el modelo que Velasco tiene delante, que no es otro que $C$, el cual lee: nadie te lo vee hazer (mientras $B \mathrm{Dvi}^{\mathrm{v}}$ trae nadie te lo vera hazer, y $A \mathrm{Diiii}^{\mathrm{v}}$ nadie te lo vea hazer; Medina, que todavía no se conocía, lee, como Amberes, nadie te lo vee hazer (f). Por cierto, que Rodríguez, no cita estos pasajes por los originales, puesto que cambia $c$ por $z$ y acentúa verá, todo ello a la moderna.

Por lo que respecta a doctrina punctandi, la Orthographia dedica un breve apartado a tratar «de los puntos y distincion de las partes de la oracion, o razones». Recoge la tradición clásica griega y latina, y propone un sistema de puntuación modernizante: punto, dos puntos o colon, coma o medio punto, interrogante, admirativo y paréntesis. Da noticia del recientísimo punto y coma pero se desentiende de él "porque ésta es mucha particularidad, y menudencia para escriptura Castellana ${ }^{51}$. En todo caso, se muestra con

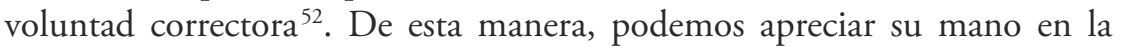
puntuación del Lazarillo, en la que se revela una intención normativa según

50. Op. cit., p. 112.

51. P. 288.

52. Por ejemplo, acabando de tratar de puntos, cola y comas, con referencia a cláusulas, partes y miembros de la cláusula, e indicar en qué ocasiones se ha de usar cada signo, concluye con esta imperación: "Como quiera que sea, entre vna y otra parte, no se deue poner punto jamas, si no fuere en alguno de los lugares señalados» (p. 289). 
pautas similares a las que se verán, aunque más definidas y regulares, en la puntuación del Quijote de $1605^{53}$.

La edición de Velasco tiene una densidad de puntuación muy superior a los impresos de 1554 . Frente a la proporción de un signo de puntuación por cada 8,48 palabras de Amberes (las otras tres tienen una proporción muy similar), el impreso censurado trae un signo por cada 6,25 vocablos. El número de signos añadidos a partir del modelo (Amberes) suponen más de la cuarta parte del total $(26,21 \%)$. Utiliza, como la antuerpiense, el punto, los dos puntos, la coma, el paréntesis y el interrogante. Como ella, no emplea el punto y coma ni el admirativo. De las 598 comas que añade, 186 preceden a la conjunción $y$, y 102 a la conjunción que, normas ambas documentadas desde la antigüedad y que todo buen humanista conoce y aplica ${ }^{54}$, y que no desconoce Velasco, quien se refiere constantemente en su tratado a los modelos griego y latino, que obran asi ${ }^{55}$. A un criterio igualmente firme desde los antiguos responden otras 20 comas que añade Velasco para separar el vocativo ${ }^{56}$. Contribuye a la recta lectura del texto la inserción

53. Cfr. Fidel Sebastián, «La puntuación del Quijote», Anales Cervantinos, Vol. XXXIX, CSIC, Madrid, 2007, pp. 101-145.

54. Vid. infra nota 56.

55. Desde el comienzo del capítulo «De los puntos y distinción de las partes de la oracion, o razones» se honra en referir su enseñanza a lo que enseñan los maestros de la antigüedad clásica: "Como de juntarse, o apartarse las partes, resulta en las palabras nuevos sinificados, assi tambien de ajuntarse, o apartarse las partes de la oracion, vnas con otras suceden diferentes sentidos, y sentencias [obsérvese el modo de colocar coma delante de $y$, según el criterio mencionado]: y assi para distinguir las palabras y razones dudosas [línea muy prieta que evita una coma prescindible], y aplicarlas a la parte que conuiene, y para denotar los tiempos y lugares, donde hablando, se descansa, y leyendo, se ha de alentar, y hazer pausa, usa la escriptura Griega y Latina, y las demas de, [sic] tres, o quatro maneras de puntos:» (Orthographia, p. 286).

56. Es muy interesante, a este respecto, la ley de carácter general que había recogido en 1540 el humanista, escritor e impresor E. Dolet en su breve tratado sobre la puntuación: "Devant que de venir aux aultres poincts, ie te veulx advertir, que le point à queue se mect devant ce mot, ou: semblablement devant ce mot, \&.» (siguen ejemplos). Si ou o \& están doblados -indica-, sólo se puntúa el segundo, como en el ejemplo que sigue: «Il a tousiours esté constant \& en bonne fortune, \& en maulvaise». Étienne Dolet, De la punctuation de la langue Francoyse, Lyon, 1540, p. 21. Esta forma de puntuar no es exclusiva de ninguna lengua en particular: «Si toutes langues generalement ont leurs differences en parler, \& escripture, toutesfoys non obstant cela elles n'ont qu'une punctuation seulement: \& ne trouveras, qu'en ycelle les Grecs, Latins, Francoys, Italians, ou Hespaignolz soient differents", p. 17 (véase la transcripción del opúsculo en el apéndice de Puntuación, humanismo e imprenta, pp. 90-94).

El criterio más o menos mecánico de asociar un signo de separación a determinadas conjunciones es muy antiguo: Diomedes en su Ars Grammaticae (ca. 350) indica que se ha de puntuar, entre otros casos, ante aut conjunción, si no se abusa, y ante caso vocativo, y ante 
de 4 interrogantes donde no había ninguna puntuación y la conversión de 17 comas, 5 signos de dos puntos, y 3 puntos seguidos, en otros tantos interrogantes, lo que hace que un total de 29 oraciones interrogativas sean restituidas a su recta lectura. Con intención ordenadora del texto, cambia 55 comas por sendas señales de dos puntos, y convierte 27 comas en punto y seguido.

Todos los errores de puntuación compartidos por dos o más de las ediciones de 1554 de que se ha dado cuenta más arriba (apartado III), son enmendados por Velasco, excepto tres que son, precisamente, comunes a todas ellas. Se trata de:

$B$ Eiii $Y$ no es buena maña de saludar vn hombre ha otro / dixe yo.

Dezirle que le mantenga Dios.

Con idéntica puntuación en $A, M y$ y , que repite Velasco $(V)$ :

$V 411^{\mathrm{V}} Y$ no es buena manera de saludar vn hombre a otro, dixe yo.

Dezirle que le mantenga Dios?

La edición de Velasco hereda el error consistente en no separar adecuadamente la interrupción de una frase pronunciada en estilo directo. Influenciado el primer copista, corrector o componedor por la fórmula 'dixe yo' que parece reclamar el punto -signo habitual en las cuatro ediciones para introducir una frase en estilo directo-, no advierte que la fórmula mencionada, en esta ocasión, constituye un inciso tras el cual continúa la frase que interrumpe. Velasco no advierte el error y lo reproduce. Rico puntúa de la siguiente

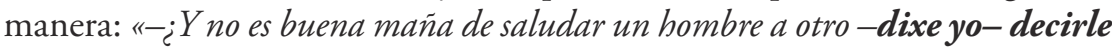
que le mantenga Dios?» 57 .

El segundo error de puntuación común a las cuatro y que reproduce Velasco es:

$B$ Eiiii Ya quando assienta vn hombre con vn señor de titulo, todavia passa su lazeria. Pues por ventura no ay en mi habilidad para seruir y contentar a estos.

Igual en $A, M, C$ y $V$ :

$V 412$ Yà quando assienta hombre con vn señor de titulo, todavia pássa su lazeria, pues por ventura, no ay en mi habilidad para seruir y contentar a estos.

sed, y ante quoniam, etc. (cfr. ibid., pp. 69-71 y 79-81).

57. Francisco Rico, p. 100. 
Falta en todos los casos el interrogante al final de la frase. Las ediciones modernas restituyen al texto el signo de interrogación: «Ya, cuando asienta hombre con un señor de título, todavía pasa su lacería. Pues ¿por ventura no hay en mí habilidad para servir y contentar a éstos??» ${ }^{58}$.

El tercer error vuelve a serlo a cuenta del diálogo, que tanta complejidad comporta en su puntuación. En este caso, el inciso 'dizen ellos' queda manco de una mínima separación de la frase que interrumpe:

$B \mathrm{Ev}^{\mathrm{v}}$ Sin duda dizen ellos esta noche lo deuen de auer alçado y lleuado a alguna parte.

Igual en $A, M, C$ y $V$ :

$V 413^{v} \operatorname{Sin}$ duda dizen ellos ésta noche lo deuen de hauer alçado, y lleuado a alguna parte.

Velasco hereda y repite, inadvertidamente, la ausencia de acotación. Rico transcribe así el pasaje: "-Sin duda-dicen ellos-esta noche lo deben de haber alçado y llevado a alguna parte» ${ }^{59}$. Hubiera bastado un par de comas. Su ausencia la podemos considerar error compartido con la edición de Amberes, que, a su vez, lo comparte con las otras tres ediciones de 1554.

\section{CONCLUSIONES}

De los resultados obtenidos tras el estudio pormenorizado de la puntuación en los cuatro impresos del Lazarillo de 1554 -y de la edición castigada de Velasco, 1573-, no se puede deducir un stemma determinado; pero sí cabe afirmar que cualquiera que se quiera dar por bueno deberá estar conforme con las siguientes conclusiones:

$1^{\text {a }}$. Los cuatro impresos de 1554 se demuestran derivados en última instancia de un arquetipo impreso común: así lo prueban los abundantes errores comunes de $B, A, M$ y $C$, y lo corrobora la altísima proporción de pasajes puntuados por los cuatro en el mismo lugar (63,66 \%).

58. Ibid., p. 104.

59. P. 107. 
2a. La edición de Amberes se ha de situar en una rama baja del stemma. Para evidenciar el poder conclusivo de la argumentación utilizada, traemos aquí de nuevo uno de los errores comunes recogidos más arriba, el primero de los reseñados entre los compartidos por $B, A$ y $M$ :
B Avi Despues que cerraua el candado y se descuydaua pensando que yo estaua entendiendo en otras cosas. Por vn poco de costura que muchas vezes del vn lado del fardel descosia y tornaua a coser: sangraua el auariento fardel socando [sic] / no por tassa pan: mas buenos pedaços: torreznos y longaniza:

El punto, que reproducen $A$ y $M$, yerra la lectura, dejando la frase inacabada, sin verbo principal. $C$, en cambio, corrige donde las otras ediciones han transmitido un mismo error:
C A8 despues que cerraua el candado y se descuydaua pensando que yo estaua entendiendo en otras cosas, por vn poco de costura que muchas vezes del vn lado del fardel descosia y tornaua a coser, sangraua el auariento fardel sacando no por tassa pan, mas buenos pedaços, torresnos y longaniza,

El error es craso en las tres que traen punto. Fácil de sanar, como hace $C$. Pasar de la mala lectura a la buena es muy fácil, pero no al revés. Pero es el caso que tres ediciones incurren en el mismo error de bulto. Sólo si se admite que Amberes es una rama baja, se explica esta situación: lo que ha sucedido es que lo erróneo ha sido corregido posteriormente, al menos en un caso. No es verosímil, en cambio, la posibilidad de que la lectura correcta, la de Amberes, hubiera sido deturpada por diversas ediciones posteriores -estuvieran o no ligadas entre sí por una dependencia directa-: se impone la ley de que es fácil sanar, difícil deturpar, y más difícil todavía cometer el mismo error en ediciones diferentes.

$3^{\text {a }}$. Burgos se sitúa en un tramo alto de la transmisión del texto. El hecho de que compartan errores con $B$, separadamente, $M, M-A$ y $M-A-C$ exige reconocerlo -a no ser que se piense que los errores se han ido produciendo poligenéticamente, lo cual no es sostenible desde ningún punto de vista. Además, Burgos no tiene -como se refleja en la tabla 2- errores comunes con las ediciones que Blecua considera más alejadas (Alcalá y Amberes) ${ }^{60}$. Burgos

60. Esta posición del impreso de Burgos con respecto a los otros ya había sido manifestada por Rico en el stemma que sugería en 1970 («En torno al texto crítico del Lazarillo de Tormes», Hispanic Review XXXVIII, pp. 405-419), que es el mismo que propondría más tarde Blecua en su edición del Lazarillo, publicada por Castalia en 1972. 
se puede considerar, finalmente, entre las ediciones que hoy día conocemos, la más próxima al primer arquetipo impreso.

$4^{\mathrm{a}}$. Las conclusiones anteriores se compadecen con los stemmata de Blecua ${ }^{61}$ y de Rico ${ }^{62}$, y contradicen los que proponen Ruffinatto ${ }^{63}$ o Carrasco ${ }^{64}$.

Stemma de Blecua y Rico (2003)

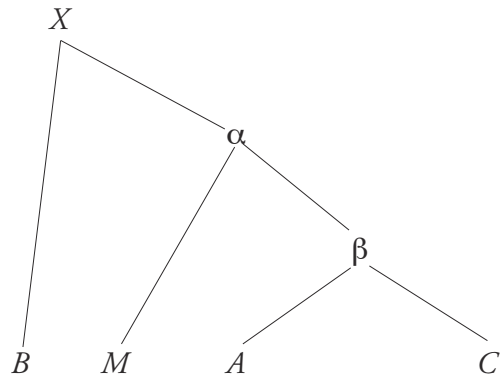

Stemma de Carrasco (1999)

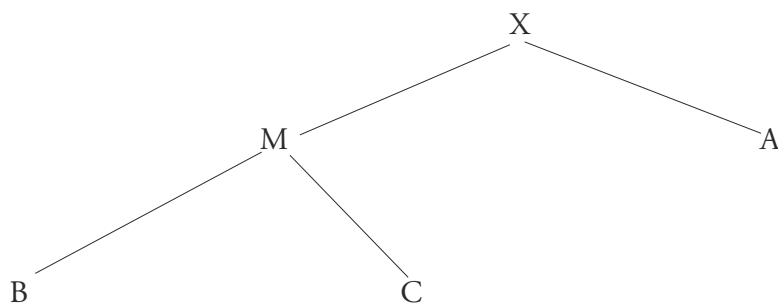

61. «La edición del Lazarillo de Medina del Campo (1554) y los problemas metodológicos de su filiación", en Salina, 17, 2003, p. 63.

62. «Lázaro de Tormes», Lazarillo de Tormes, Colección Millenium publicada por el diario El Mundo, Madrid, 1999, Lima, 2000, nota al texto, pp. 9 y 10.

63. «Notas sobre el Lazarillo de Medina del Campo 1554», Incipit, XVI (1996), pp. 189202. Este mismo stemma lo reivindica en Las dos caras del Lazarillo: texto y mensaje, Madrid, Castalia, 2000.

64. Félix Carrasco, «La transmisión textual del Lazarillo a la luz de la edición de Medina del Campo (1554)», Edad de Oro, XVIII (1999) pp. 47-70. 
La diferencia fundamental entre ellos radica en que el primero sitúa a Burgos en un tramo alto de la transmisión -como nosotros creemos probar-, mientras que los otros colocan esta edición en un lugar más distante del original. En el siguiente gráfico se puede apreciar la justificación del stemma de Blecua y Rico por los errores comunes de puntuación en las ediciones de 1554.

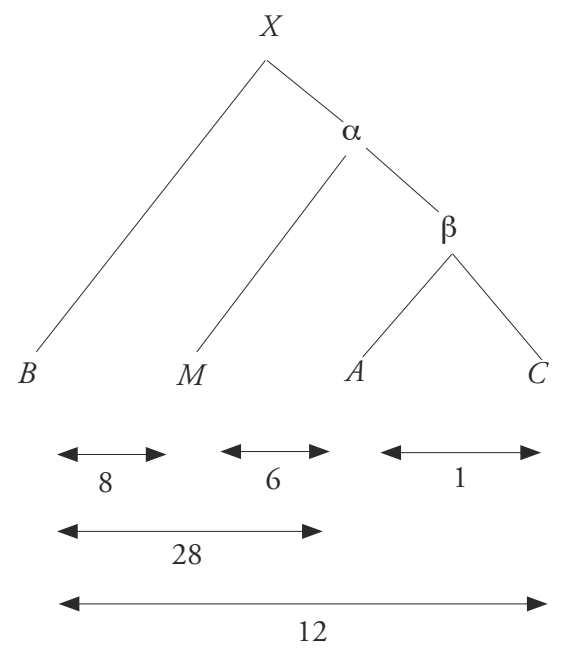

5a. Finalmente, y respecto a la edición de Velasco, la confrontación de sus variantes con la Orthographia que publicó años después -hasta ahora desconocida o ignorada por la crítica-, niega la justificación ope codicum que Ruffinatto postula invocando un modelo desconocido anterior a 1554, que sería el «arquetipo de los arquetipos».

La comprobación de que las variantes obedecen a criterios ortográficos propios de Velasco prueba que las desviaciones intencionales se deben atribuir a la voluntad del editor: son intervenciones ope ingenii. No hay motivo para dudar de que el Lazarillo castigado está confeccionado a partir de uno o varios ejemplares de la edición de Amberes de 1554 (la edición que denominamos $C$ ).

1 de octubre de 2007 